CuPAUAM. 18-1991, 299-317

\title{
EL CONJUNTO MONACAL VISIGODO DE SAN MIGUEL DE LOS FRESNOS (FREGENAL DE LA SIERRA, BADAJOZ): ESTUDIO PRELIMINAR
}

\author{
LUIS BERROCAL RANGEL \\ UNIV. AUTONOMA DE MADRID \\ RAFAEL CASO AMADOR \\ UNIVERSIDAD NACTONAL A DisTANCLA \\ (MERTAN)
}

\section{Resumen}

Conocidos los importantes restimonios literarios que hablan de la presencia de Alanos, Suevos y Visigodos sobre los territorios extremeños y alentejanos del Suroeste, sólo hasta fechas recientes la Arqueología no ha venido a paliar un vacío monumental que, apenas, era amortiguado por las colecciones acontextuales de Badajoz, Mérida o Beja.

A Santa Olalla, Santa Lucfa, El Gatillo o Vera Cruz de Marmelar, y otras construcciones, como San Pedro y Santa Eulalia de Merida, que puede considerarse dentro de este perfodo, viene a sumarse este nuevo conjunto. Se va conformando así un panorama arqueológico que responde claramente a la importancia que tales comunidades tuvieron en Extremadura, durante los siglos previos y posteriores a la invasión musulmana.

\section{Summary}

In spite of numerous testimonies from literary sources about barbarian presence in the Southwestern Peninsula, the archaeological evidence was limited to a few monuments and rich collections of art's pieces from Badajoz, Mérida or Béja.

In last years, increasing investigations allow to get an important group of archaeological places that confirms the importance of Alans, Sueves and, then, Westgoths on Extremadura (San Pedro, Portera, Santa Lucta, Santa Eulalia, etc.). In these pages, we introduct a new one, sited in the neighbourhood of Portugal and Andalucia.

Hasta afios recientes el panorama arqueológico del período abarcado por la dominación "bárbara", y especialmente visigoda, se caracterizaba por una cierta escasez de yacimientos bien definidos y conservados (Camps, 1963; Palol,1954 y 1967; Corzo,1989; Caballero,1989) frente a la abundancia de elementos arquitectónicos de carácter ornamental y suntuario, sueltos y sin con- 
texto original conocido, que en algunas zonas alcanzan auténtica importancia (véase Cruz Villalón, 1977 y 1985).

Afortunadamente, tal panorama va cambiando gracias a los nuevos descubrimientos de construcciones que, enmascaradas en edificios y ruinas tardomedievales, han llegado a nuestro dias en mejor estado de conservación de lo que, a primera vista, cabría esperar.

En Extremadura, al menos, estos son los casos de un buen grupo de iglesias y basílicas, como las de Ibahernando, El Gatillo, o Santa Lucia del Trampal, en Cáceres, o de San Pedro y Santa Eulalia, en Mérida (Cerrillo, 1981 y 1983; Cruz Villalón, 1986; Andrés Ordax, 1981, 1983 y 1986; Caballero Zoreda, 1987 y 1991; Caballero y Rosco, 1988-a y -b; Caballero et aliz 1991; etc.), y es el de este interesante conjunto monacal de San Miguel de los Fresnos (Fig.:1).

\section{LOCALIZACION Y ESTUDIO DEL ENTORNO}

San Miguel es una ermita de nave única, estilo gótico y construcción medieval (ss. XIV/XV) cuyos restos se yerguen, en postrera ruina, bajo las sombras de la vieja y frondosa fresneda que le ha dado nombre (1). Situable por las coordenadas $38^{\circ} 11^{\prime} 15^{\prime \prime}$ N. - 6 $35^{\prime} 18^{\prime \prime}$ O. (Greenwich), hoja 875-IV del Mapa Topográfico Nacional de España, se localiza en el término municipal de Fregenal de la Sierra, dentro de los confines sudoccidentales de la provincia de Badajoz.

Geográficamente, su entorno corresponde a las más occidentales estribaciones de Sierra Morena, con alturas que oscilan entre los 500 y 1000 m. s.n.m. y numerosas corrientes fluviales menores, subsidiarias del río Ardila, en la cuenca del Guadiana. Las precipitaciones $(750 \mathrm{~mm}$. de media anual, $950 \mathrm{~mm}$. de ETP), abundantes por la influencia atlántica, se ven condicionadas por los fuertes estios que proporcionan al clima mediterráneo un carácter oscilante entre subhúmedo y continental (Barrientos, 1990, 45-46; González Ceballos, 1988, 20-21 y 28; Mapa de Cultivos..., 1988,12-13).

Geolbgicamente, se asienta sobre una formación típica del Occidente Peninsular, con una base cámbrica donde coinciden pizarras y cuarcitas con bolsones de granitos y granodioritas. El yacimiento se emplaza, precisamente, sobre una línea de contacto entre tales formaciones (Mapa Metalogenético de España, Hoja 67-68; Mapa Geológico y Minero, Hoja 875).

Ambas favorecen una generalizada riqueza minera en la comarca ardileña, aunque no haya yacimientos en el entorno inmediato del lugar. Los más cercanos se localizan a cinco kilómetros al Swr, centrados en las menas férricas de Valera, explotadas desde la prehistoria y en cuya razón está la cercana citania céltico-lusitana de Nertóbriga (Quesada et alii, 43-44; Mapas de Cultivos, 1988,29). No parece existir una directa relación entre los recursos mineros y San Miguel (Domergue, 1987 y 1990), al contrario de lo deducido si se se analizan otras riquezas, como las agropecuarias y comerciales.

Aunque la zona en cuestión es mayoritariamente de vocación ganadera (cerdos y bóvidos), el Mapa de Cultivos (Hoja n॰ 875 - Jerez de los Caballeros) permite observar que en tres kilómetros, en torno al yacimiento, se concentran las únicas masas de olivares apartadas del núcleo urbano de Fregenal (Fig.:2.1.). Edlo no tiene correspondencia con el sistema de explotación actual que va en detrimento de estos árboles mientras se incrementan las tierras de pasto y encinar. La explotación del lugar es, por tanto, propia de la ganadería extensiva, en las conocidas dehesas (Pérez Díaz, 1988).

(1) Quezernos agradecer las ayucias recibidas de nuestros companteros D. Aurelio Salguero Matin, de Higuem la Real, en el traramiento del yacimienro y de D. Andrés Oyola Fabiann, de Segara de León, a quien debemos el hallazgo del cenante de altar siruado en esra villa y de la imposta hallada en Fregenal de la Sierra. Por úitimo dełrernos a la amabilidad del Dr. Jose Luis De la Barresa Anzón, del MNAR de Mérida, el conocimiento del capitel de Arroyomolinos de Lesn. 


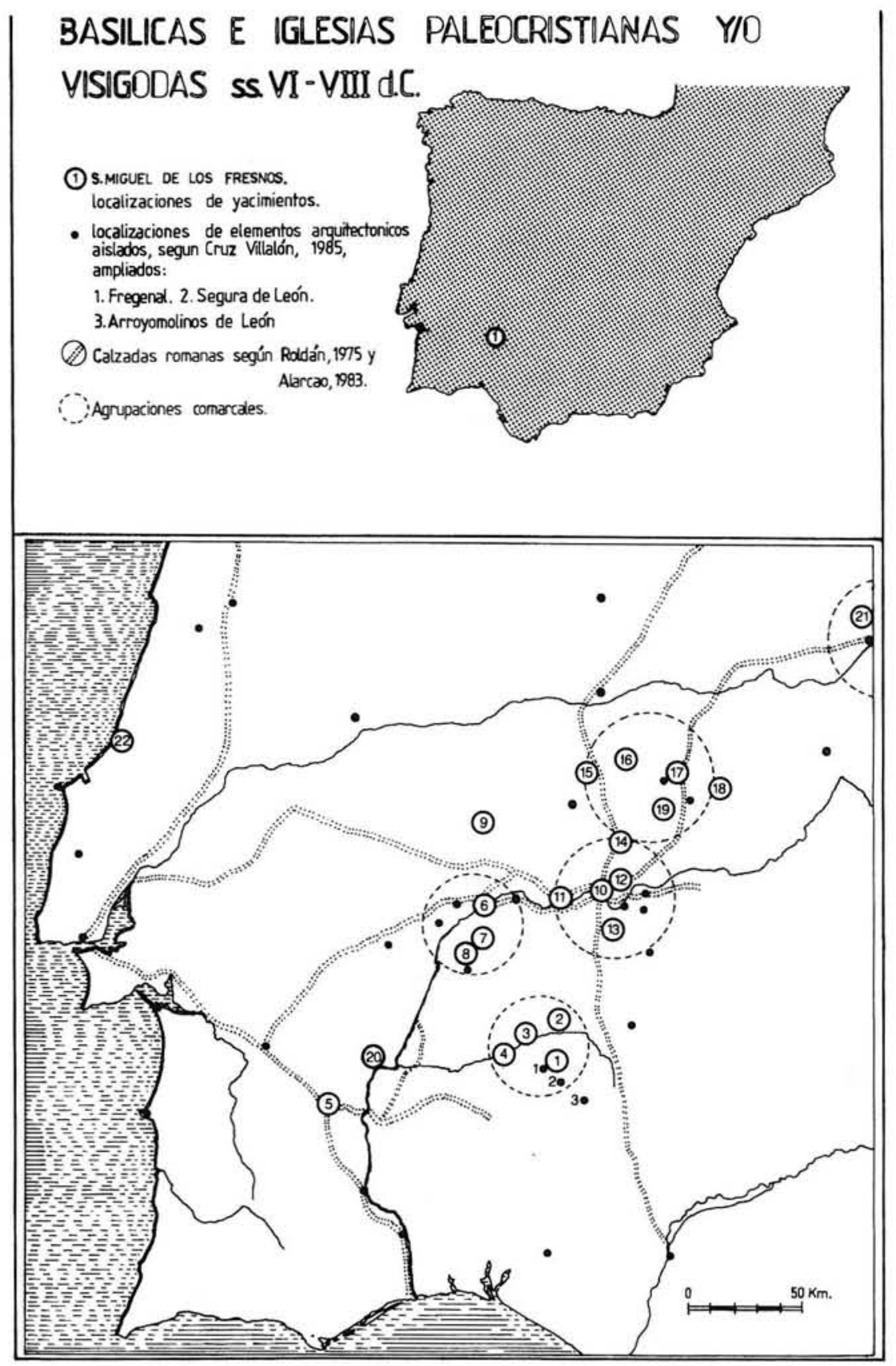

Fig. 1: Dispersión y concentración de los restos constructivos altomedievales en el Suroeste: 1: San Miguel de los Fresnos; 2: Burguillos y Valverde de Burg.; 3: Jerez y Brovales; 4: La Mata de San Blás; 5: Beja; 6: Badajoz; 7: La Cocosa; 8: Valdecebadar; 9: Los Santiagos; 10: Mérida; 11: Torre Aguila; 12: Casa Herrera; 13: Concejil del Palomo; 14: Santa Lucía del Trampal; 15: Santa Olalla; 16: El Gatillo; 17: Las Corias; 18: Portera; 19: Ibahernando; 20: Vera Cruz de Marmelar; 21: Santa María de Melque; 22: S. Giâo de Nazaré. 

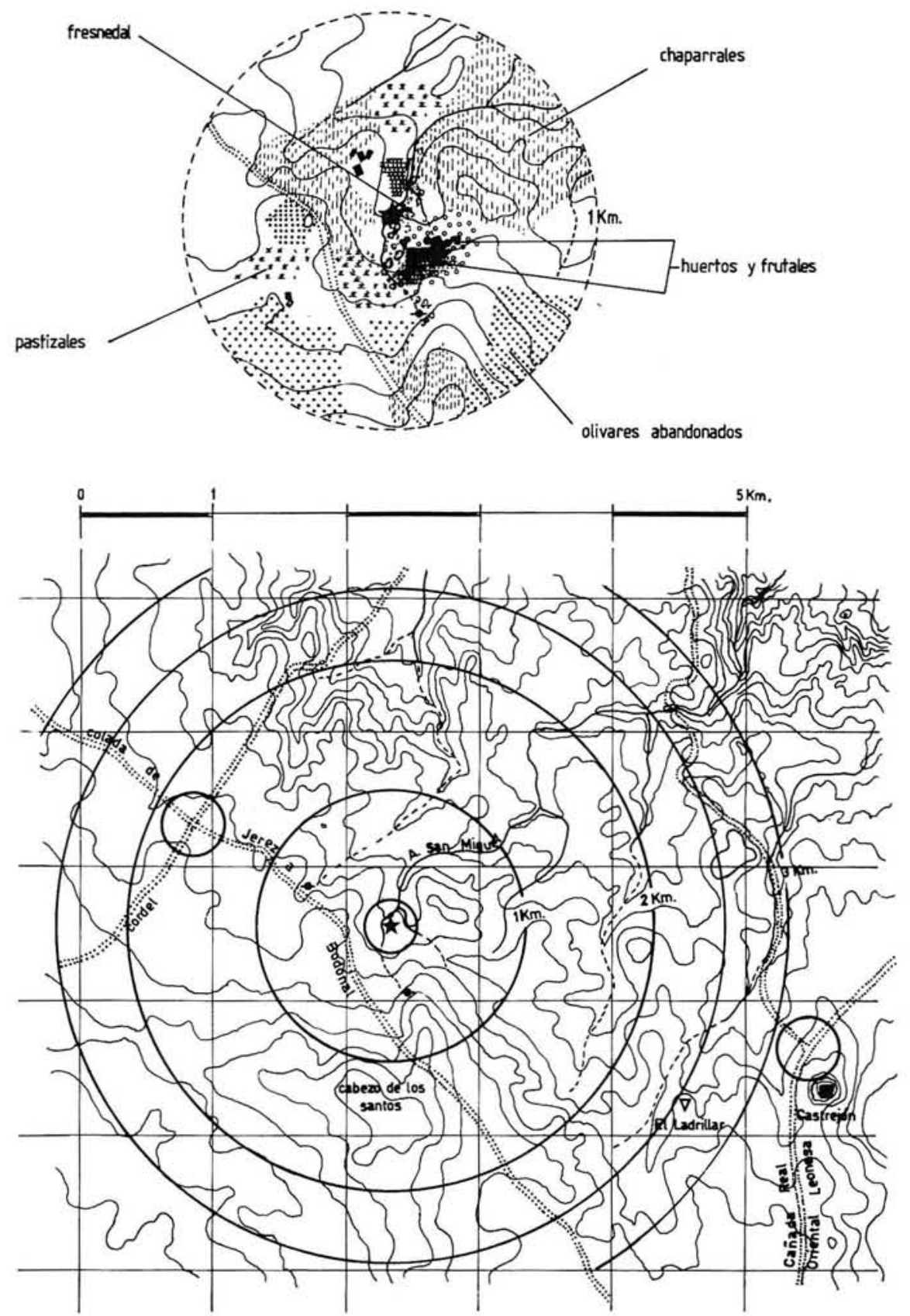

Fig. 2: Entornos inmediatos de San Miguel de los Fresnos. 
Sin embargo la concentración de viejos olivares (que en estas tierras son, básicamente, de implantación dieciochesca) tiene su respuesta en las numerosas huertas abandonadas que se localizan alrededor del paraje. Hoy sólo restan casas en semirruina y numerosos árboles frutales (perales, merribrilleros y manzanos) dispersos y asilvestrados. La zona es especialmente rica en aguas y ello favoreció un aprovechamiento intensivo del terreno que las condiciones modernas hacen inviable.

Este paraje de San Miguel se encuentra regado por un arroyo homónimo cuyo cauce estrecho y profundo responde a importantes caudales temporales de naturaleza torrencial. Se trata de una pequeria corriente que nace en el mismo paraje, en las numerosas fuentes del entorno, de las que sólo la propia de San Miguel queda en uso. El arroyo es subsidiario del Pedruégano que, a su vez, desemboca en el río Ardila.

En torno al cauce de este importante río se van localizando numerosas vías de comunicación, heredadas por las cańadas, caminos viejos y carreteras actuales, que otros estudios arqueológicos han demostrado estar en uso desde, al menos, época protohistórica (Berrocal,1992). De esta forma atraviesan la comarca dos de las más importantes cañadas mestefias, la Occidendal y la Oriental Leonesa, estando comunicadas entre sí por numerosos cordeles y cañadas menores (Garcia Martín,1988, 434-437). Dos de estos, la colada de Jerez de los Caballeros a Bodonal y el cordel mesteño de Fuente Romero, se cruzan a kilómetro y medio al Oeste del yacimiento en estudio, mientras la misma Cañada Oriental Leonesa pasa a tres kilometros al Este (Fig.: 2.2).

El emplazamiento de yacimientos romanos (en las cercanías, el Ladrillar y el castrejón de Bodonal), que son los mas prospectados, ha permitido confirmar la utilización de tales caminos en tiempos antiguos y por ello no es una exageración si se contemplan en uso durante la Alta y Baja Edad Media.

\section{DESCRIPCION Y ANALISIS DEL YACIMIENTO}

En la actualidad, las prospecciones superficiales sólo permiten la constatación del fuerte talud que, en ciertos tramos, se revela como propio de un recinto amurallado, adaptado a un meandro del arroyo y abarcando una superficie aproximada de $0.6 \mathrm{ha}$. (Fig.: 3).

Dentro de tal espacio, densamente poblado por fresnos y algunos viejos olivos, se localizan los restos de la ermita medieval de la que se conservan los muros perimetrales de la única nave, sólo cubiertos por las desnudas piedras de dos magnificos arcos ojivales fajones. Con una entrada laceral, también en estilo gótico, orientada hacia el Sur, se accede a la nave y a un magnífico ábside, cubierto con bóveda de canión que acaba en bóveda de cuarto de esfera.

En torno a tal construcción afloran los restos de gruesos muros que parten de las diversas esquinas exteriores del ábside o rodean la nave tardomedieval.

Distanciados una veintena de metros $(23 / 24 \mathrm{~m}$.) hacia el Sur, y con la misma orientación que la iglesia y sus muros circundantes, se localizan otros de similar aparejo y mayor grosor, que en ángulo recto parecen responder a un importante y destacado edificio de planta cuadrangular.

De ell se reconoce un tramo de más 8 metros acabado en esquina, con sillares descubiertos por viejas actuaciones clandestinas. La clata elevación del terreno en este extremo del recinto y, especialmente, en torno a esta última construcción, permite suponer que en él se localizan sus restos principales (Fig.:3)

Este yacimiento tiene toda una larga y desconocida tradición histónica, con referencias que pretenden remontarse a épocas paleocristianas y a la Alta Edad Media. 


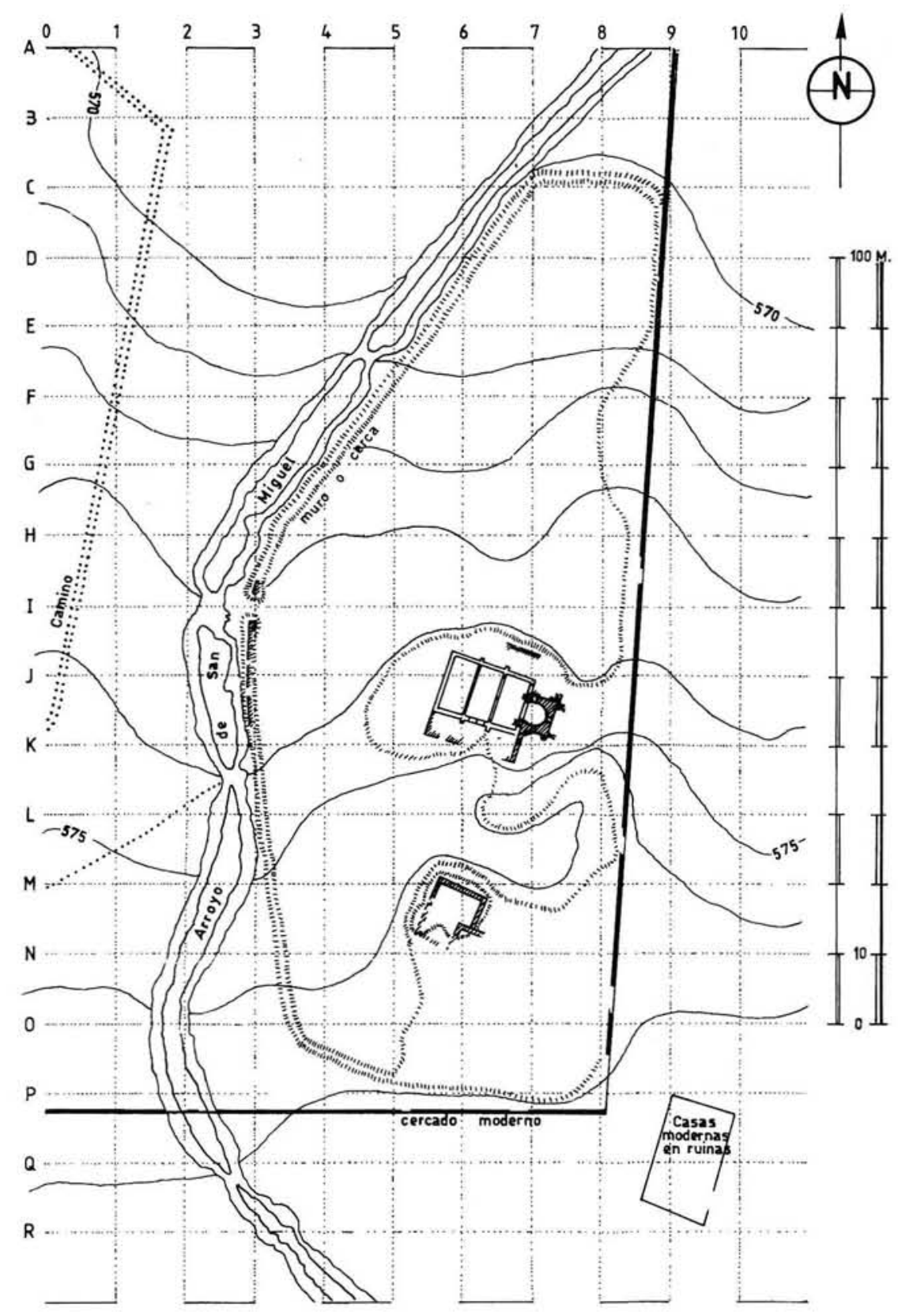

Fig. 3: Planta del yacimiento, con el talud de la muralla. 
Así fueron recogidas por los historiadores locales, quienes proporcionan los primeros datos modernos publicados sobre las ruinas (Quintero Carrasco,1981,112; Sánchez Cid, 1843,39-42), remitiendo a tradiciones locales de vieja raigambre (como testimonia, concluyentemente, el topónimo "Cabezo de los Santos" del cerro cercano).

Informa Sánchez Cid de una cita de la Crónica General De España de Ambrosio de Morales (1574/1586, tomo IX, cap.16, fol.365) sobre la presencia en el lugar de una inscripción goda, en la que se refiere el enterramiento del Abad Honorio, mención que, así mismo, recoge el Padre Vivar (Notas a Marco Maximo, 1573) como procedente de las Antigizedades de Sevilla (libro IIIo, cap.69) de Rodrigo Cato. Indica, a su vez, este célebre historiador que en casa de Arias Montano se guardaba otra inscripción referida, esta vez, a la tumba de San Exuperancio.

De Sánchez Cid tomamos, además, una interesante descripción que informa de la existencia de aguas medicinales:

"En la actualidad se denomina las buertas de S. Migueh, que lindan con las nuinas de este templo. Tradición hay que aquí estuvo un monasterio de monges de $S$. Benito, en el que parece vivieron los Santos Honorio y Exuperancio. De estos bienaventurados siervos de Dios se refiere, que con el agua de la fuente del monasterio curaban los enfermos, que á ellos acudian en sus aflicciones y padeceres." (Sánchez Diaz, 1843,39).

Con todo, las reservas que estas informaciones nos suscitan son grandes, puesto que no conocemos resto contrastado que confirme tales afimaciones, aunque diversos autores eclesísticos recogan esta presencia. De estos, sin duda, son los párrafos debidos a Solano de Figueroa, en el siglo XVII, los más interesantes:

"254. de este son las memorias de S. Exuperançio Abad, disçipulo del gran patriarca S. Benito, de quien trata $S$. Máximo, como insinuando que auia muerto el año de quinientos y setenta y ocho; quando dixo: Per bos dies Nertobrigae; vel concordiae, floret exuperantius Abbas Benedictinus, discipulusque S. Benedicti, de quo tale legi elogium. Nertobrigae, quate concordia dicitur in Baetica, floret exuperantius vir Dei, et ibidem ut sanctus habetur, y reparo el Mo viuar que habló maximo de $\mathrm{S}$. exuperançio, como de quien auia muerto; pues diçe que tenia epitafio ó elogio su sepulcro el santo Patriarca le enbió con otros conpanieros en numero de doze a españa.....y lo diçe el año 612. (.....) S.exuperançio fue Abad del monasterio de Panplona...... si desde Toledo, $\delta$ de Cardeña, bajó á nuestra Prouinçia no se sabe; pero es çierto que llegó á Frexenal, llamada entonçes Nertobriga, con titulo de abad á fundar el Religioso y autorizado conuento que alli tuuo la orden -yá estaba en el por los ańos de quinientos y sesenta y dos, como dice M. Maximo, exuperantius cum alis monachis Benedictinis concordiae in Baetica, quae etiam Nertobriga dicitur, mirabilis habetur, y alli y en su comarca le tenian todos por hombre maravillo y santo. (.....) fue su diçhoso transito en Frexenal á los veintisiete de mayo del año quinientos y setenta y ocho, como dixo $M$. Maximo, y se conprueba con la lapida ó piedra que se halló en nuestros tiempos, y que diçe assi:

+ exuperantius. Famulus Dei. vixit

annos plus minus LXXVIII, requieuit

in pace. sub. VI. KL. iunias. AEra

$D C X V I$

en poco discrepa esta inscripçion de como la trae el dor. Rodrigo caro.....Pero como vá escrita aqui la copio el P. Antonio Ruiz de la conpa de Jesus, el primer Rector que tuuo el collegio de Frexenal, y el primero que la trasladó. (....) Sólo es reparable lo que escribe el Dor. Rodrigo Caro en los pretermissos, que la piedra sepulcral de $\mathrm{S}$. exuperançio se halló en las ruinas de Valera, á 
quien llama Nertóbriga, no lejos de Frexenal; constando de la carta referida que se halló en Frexenal, dentro de la ermita de S. Antón; y es çierto que el monasterio no estuuo en Valera, sino en su distrito, como está los más de los monasterios Benedictinos fuera de los poblados.....se halló otra inscripçion de otro Santo Abad en la misma poblaçion de Frexenal, á la puerta de la hermita que es oy de S. miguel, que vio Ambrosio de Morales, de quien los demas la copiaron, y en el lib. 12, titulo Beturia, fol. nú. 100, la pone de esta manera.

IN NOMINE DOMINI

RESPICIS AVGVSTVM PRECISA RVPE SEPVLCHRVM. HOSPICIVM BEATISSIMI HONORII ABBATIS

CAELESTIA TENENTIS REGNA. IN SAE CULA SAECULORVM AMEN.

HIC TVMVLVS HONORI ABBATTS

(Solano de Figueroa, 1930,165-167 y 171-173):

Proceda de los Llanos de Valera (al sur de Fregenal), o de la ermita de San Anton (al norte de dicha población), la supuesta lápida de San Exuperancio, no caben dudas sobre la referida a San Honorio Abad y, por tanto, todas las fuentes mantienen la existencia de un monasterio en San Miguel. No obstante, tal como conjetura Quintero Carrasco y apoya la toponímia del cerro aludido, ambas lápidas y referencias pudieran haberse localizado en este mismo yacimiento (se recuerda la relación entre la "vecina huerta de Arias Montano" y el que la inscripción de San Exuperancio estuviese en la casa del insigne humanista.

\section{LA ERMITA DE SAN MIGUEL}

La nave gótica muestra un aparejo irregular, de piedras y mortero, que contrasta con el uso, en el ábside, de hiladas de grandes sillares cuadrangulares, tallados en granito y dispuestos a seco. En muchos casos el grado de conjunción, prácticamente, no deja espacio entre piedra y piedra y, en otros, los inevitables huecos de las esquinas o de la igualación de hiladas, se rellenan con cunas (Figs: 4/6).

Este aparejo, base de la estructura del ábside, parece querer seguir una disposición "a soga y tizón" (al menos al exterior, en la cara oriental -Fig.:5) mientras gran parte de la bóveda se ha cubierto, en su relleno exterior, con hormigón de mala calidad, en bloques de pequeño tamaño ( $0.4 \mathrm{x}$ $0.2 \mathrm{~m}$. de media). Con dicho sistema, además, parecen haberse construido las bóvedas de cañón de dos salas laterales, con las que pudo formarse una construcción de triple ábside, y de las que restan, exclusivamente, los arranques de las bóvedas.

La planta provisional que hemos levantado (2) permite, junto con el análisis de los alzados, deducir las primeras conclusiones.

1.- De época moderna (ss. XVI/XVII) sería un pequeño altar conservado en el ábside, con nicho $y$ venera central, franqueado de otros dos menores (Fig.: 6).

2.- Bajo Medieval, probablemente de obra templaria, santiaguista o sevillana (ss.XIII/XV), son los restos arruinados de la iglesia rural bajo la advocación del Arcángel San Miguel. Estos restos,

(2) Queremos dejar consancia que, ante las dificaltades del terzeno, con numerosos restas sorerrados y un alto grado de desnsidad arbórea, es necesario confrontar nuestros levantamientos de plantas con otros realizables ras una imprescindible limpieza superficial. 


\section{IGLESIA DE SAN MIGUEL DE LOS FRESNOS.}

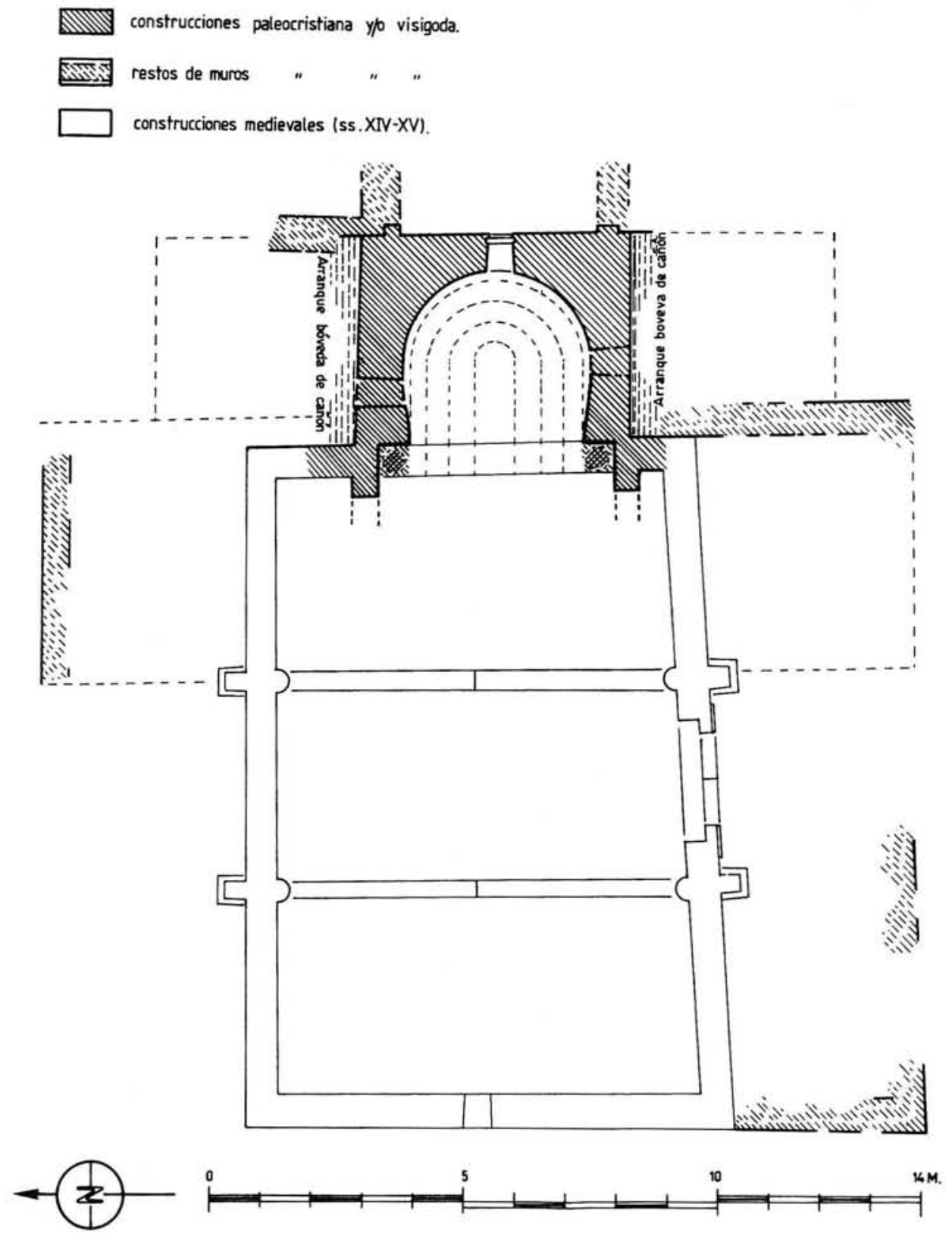

Fig. 4: Planta de la iglesia de San Miguel. 


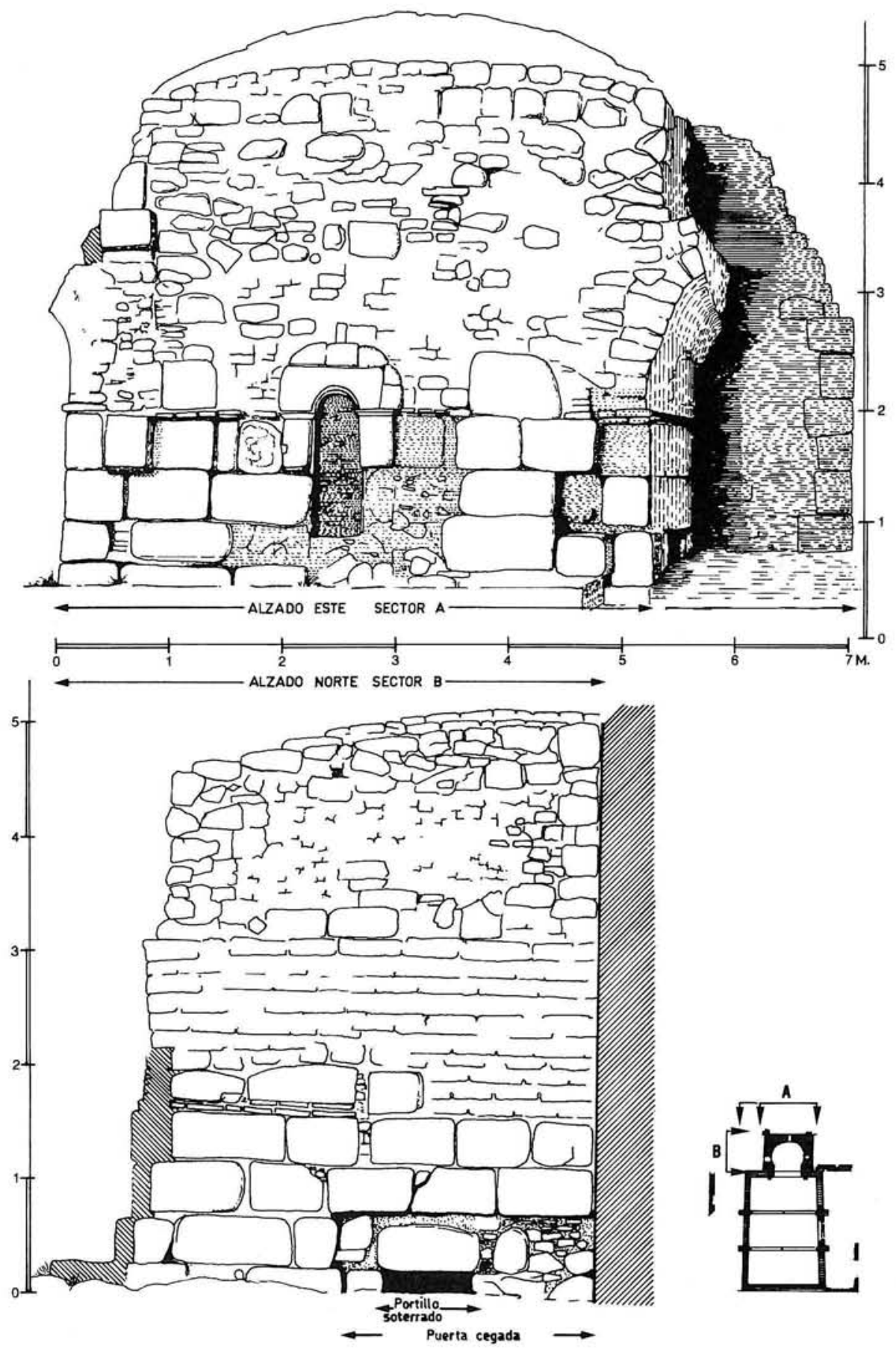

Fig. 5: Alzados Oriental y Septentrional del ábside central. 
no carentes de interés por su calidad arquitectónica, se limitan a los muros perimetrales de la nave, la entrada ennoblecida y un par de arcos ojivales, junto con las pilastras que los sujetan.

3.- Alto Medieval, de fecha imprecisa, aunque de clara tradición contructiva visiogoda, es posible que sean los arranques de las bóvedas de cañón laterales, realizados en el mismo mortero que sirve para cubrir el ábside central.

En un momento contemporáneo o, quizá, anterior pudiera fecharse la construcción de este ábside, caracterizado por los grandes sillares de granito que, a nuestro entender, son reaprovechados de alguna construcción romana o paleocristiana (al estilo "uso de retales" de Caballero, 1987,6768).

Se constata este aparejo en las tres paredes del ábside, hasta la altura de $1,65 \mathrm{~m}$. por el exterior, cuando se documenta una banda continua y estrecha de cuñas de piedras y fragmentos de ladrillos o tégulas que, a modo de tosca cornisa, es interrumpida por el vano de una ventana centrada en la pared oriental. En su extremo derecho se emplazó un fino fragmento marmóreo que, con un esquema de triple moldura, puede considerarse como un elemento de cierto prestigio.

La pieza sirve de nexo con otra cornisa o imposta, en el interior del ábside y a una altura de $2,70 \mathrm{~m}$. Construida por similares elementos de marmol, el altar moderno impide observar su remate con la ventana central, pero todo indica que ambas cornisas estarían en una misma cota, observándose, por tanto, un desnivel cercano a un metro.

Por el exterior, sirve de remate a los sillares como paramento, dado que sobre ella se reconoce el mortero, que sirve de arranque de las bóvedas laterales, mezclado con piedras irregulares y caóticamente dispersas. Pero tanto en la pared oriental, como en las otras dos, se observan sillares graníticos bien escuadrados y emplazados, como restos de la continuación de la cantería regular. Por el interior, pese a un enlucido de cal o estuco moderno, se observa con claridad la continuidad del aparejo de sillares desde el suelo actual al techo abovedado.

La citada ventana responde a las clásicos cánones paleocristianos y visigodos, alargada $(1,85 \mathrm{x}$ $0,35 \mathrm{~m}$.) y culminada en arco de medio punto, destacado por las salientes impostas. Debemos anotar que el arco se encuentra tallado en un sólo sillar que, a modo de dintel, ha sido realzado, o fajonado, mediante la ajustada adición de otros menores hasta conferirle un contorno de "herradura". En el inmediato perfil interior, una fina ranura serviria para sujetar una celosía.

Por ambas paredes laterales se constatan sendas puertas, estrechas y descentradas, con dinteles situados a una altura cercana a la de la base de la ventana y, por tanto, apenas sobresalen del nivel del suelo exterior (realmente, sólo la septentrional, más alta, es visible desde fuera).

Pero los restos más relevantes son, sin duda, el arco toral, quizá de triunfo, del ábside y su continuidad abovedada. Esta obra, parcialmente soterrada, presenta un aspecto monumental, sin duda por el tamaño de sus sillares.

La altura observable alcanza los 6,50 metros hasta la cima, de los que 5,40 m. corresponden al interior de la bóveda y del arco de entrada, que deben aumentarse en un tramo enterrado cercano a los dos metros (Fig::6).

La rosca del arco, que es lo único conservado, se compone de 19 dovelas de granito, más o menos regulares y de $0,8 \mathrm{~m}$. de longitud, junto con un hueco, en posición de contraclave derecha, ocupado por piedras de relleno. Presenta un disposición radial de los lechos de las dovelas y un extradós paralelo, hasta que se desvía al exterior, ligeramente, en los grandes salmeres.

No hay, por tanto, clave y el lugar central se situa en la conjunción de los lechos de la contraclave izquierda con el hueco indicado. Este se rellenó con dos pequeñas dovelas, dispuestas una sobre la otra mediante piedras planas. El caso confirma, una vez más, la reutilización de estos silla- 


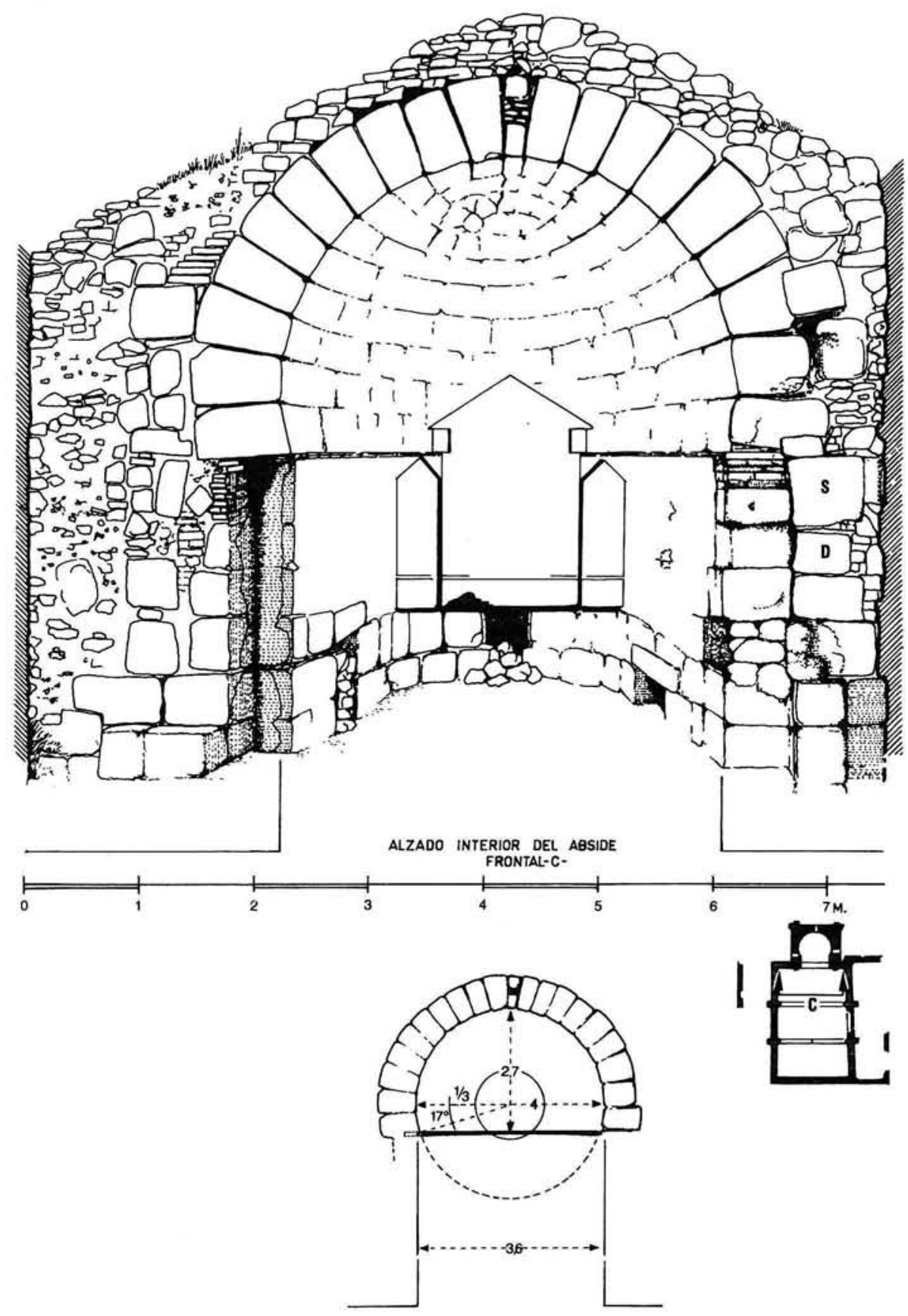

Fig. 6: Alzado y esquema del arco toral y ábside central. 
res dado que ral solución denuncia la construcción de un arco con dovelas talladas para otro. Por otra parte, se observa una diferencia en las anchuras de las pequeñas dovelas que componen esta improvisada "contraclave". El resultado final es una completa simetría que, a un lado, despliega nueve dovelas y el hueco de relleno, y al otro, son diez las contabilizadas.

La flecha del arco alcanza, desde la línea de unión de la base de los salmeres a la de la "clave", los 2,7 metros, mientras su diámetro es de 4 metros. Dado que se trata de un arco de herradura, las dovelas de arranque prolongan la semicircunferencia en $17^{\circ}$, y aproximan los apoyos hasta los 3,60 metros de luz. El peralte es ligeramente menor $(0,50$ por $0,67 \mathrm{~m}$.) a $1 / 3$ del radio, tal como parecen mandar los cónones visigodos (Camps, 1953,21;Caballero, 1977-1978; Corzo,1978).

Si comparamos estas medidas con las del arco toral del ábside de Santa María de Melque observaremos que son muy aproximadas (tanto en flecha, luz y diámetro) permitiendo suponer una ampliación de altura de poco más de metro y medio, correspondiente al tramo enterrado (Caballero y Latorre, I980,672, cuadro I, Toral E; plano 36). Como la extracción de sillares observable en la pared oriental exterior también en las esquinas, sobre las que parecería apoyarse tal arco, faltan sus columnas o pilares. De ellos, el meridional se ha sustituido por una pila de sillares y piedras, mientras la esquina septentrional aparece vacía, quizás, por haber albergado una pila bautismal o el púlpito de la iglesia gótica.

A ambos lados se observan la continuación de los muros, piezas de arcos reutilizadas ( $\mathrm{S}$ y D en Fig:6) y arranques o apoyos transversales de otros arcos o muros que alargarian, o alejarían, el ábside de las naves, por el transepto (Fig.:6). Restos de estructuras como estas, pertenecientes a la época antigua del edificio, afloran en superficie desde todas las esquinas conservadas, de manera que, proyectados en planta, permiten observar una estructura basilical de probable esquema tectangular, aunque creemos que es cruciforme (Fig.:4).

Asi se confirma con el análisis de la planta de este ábside, que no es semicircular, dado que su anchura máxima y central es de 3,70 metros, sobresaliendo $0,20 \mathrm{~m}$. de la recogida bajo el arco de entrada. La planta de herradura es, por ello, suave pero clara, con una tendencia circular que quedaría rota, quizá, por un anteábside o por el crucero, a cuyos arcos torales pudieran corresponder los arranques de los sillares aludidos.

Su abovedamiento, acabado en bóveda de cuarto de esfera se encuentra realizado con un sistema de aproximación regular de sillares muy bien dispuestos y con numerosas oquedades de grapas. Pese a este buen aspecto general su culminación resulta, de nuevo, desmañada, a causa de la necesidad de culminar el acoplamiento de los sillares en una estructura para la que no fueron hechos. Es por ello que se observa un destacado agrietamiento que, desde la línea central de conjunción del arco de entrada, penetra hasta el punto central de la bóveda de cuarto de esfera.

Como se ha indicado, la disposición en planta de los muros semienterrados, de los que afloran destacados taludes y algunos tramos con hiladas, permite tener la certeza de encontrarnos ante una iglesia de planta cruciforme y triple ábside, en el que el central presenta planta de herradura. El transepto no parece ser muy alargado, pues su dimensión transversal no le destaca, especialmente, de la anchura de las naves, de las que sólo se conoce su petímetro aproximado.

Por último, de los ábsides laterales parten estructuras hacia el Este, cuya naturaleza pudiera comprenderse dentro de diferentes construcciones adjuntas al edificio, si bien no está clara su correspondencia cronológica.

Queda referirse, brevemente, a tres piezas de arte visigodo que, si bien fueron halladas en las vecinas poblaciones actuales, pudieron proceder bien de este monasterio como de otras construcciones similares (Fig.:7). 

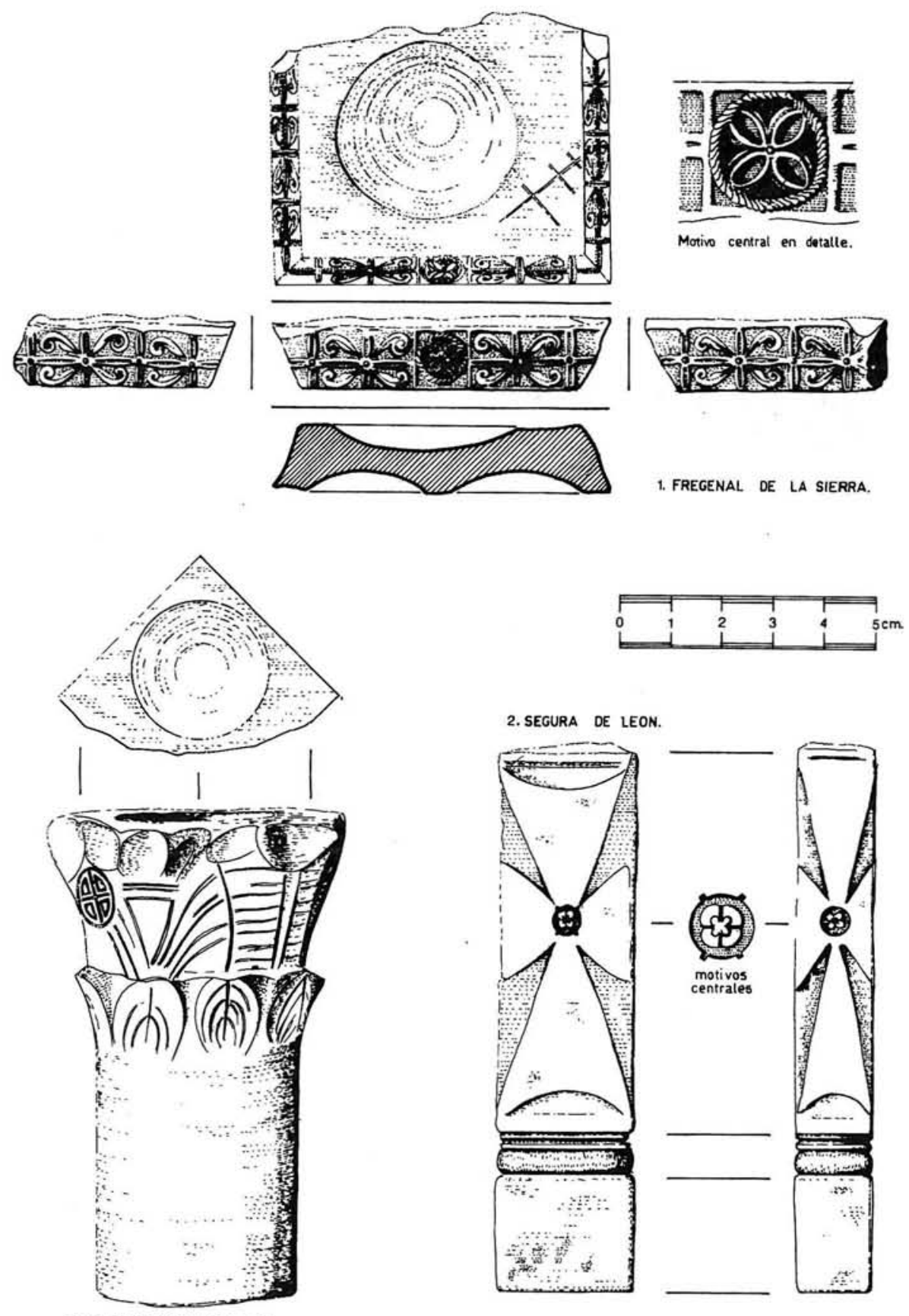

3. ARROYOMOLINOS DE LEON.

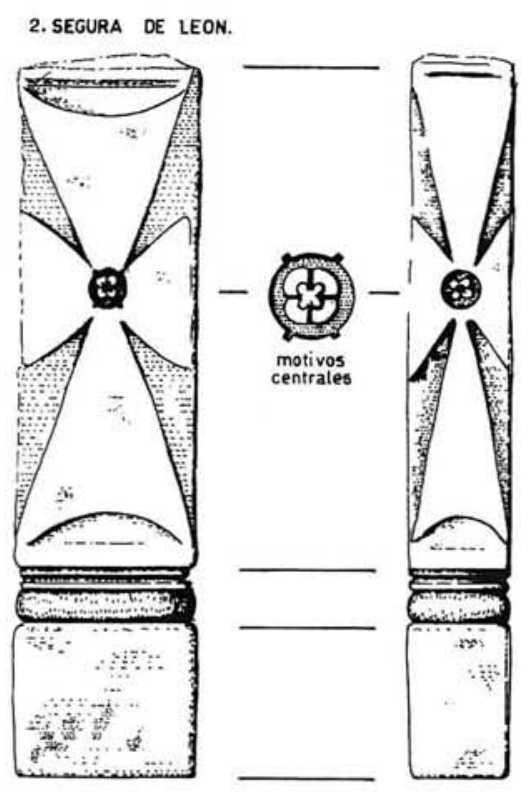

Fig. 7: Piezas arquitectónicas halladas en los entornos. 
En Fregenal de la Sierra fue localizado, en 1989, un magnifico cimacio de marmol, procedente de unas obras cercanas a la parroquia de Santa Ana (calle de la Muleta). La pieza estaba totalmente embutida en un muro en disposición que no permite suponer un emplazamiento original (Oyola Fabián,1990,23). Aunque, en 1991, pudimos documentarla gráficamente y proceder a su dibujo, actualmente se encuentra perdida.

Se trata de una pieza de muy buen arte y considerable tamaño, que contiene composiciones cuadriculadas por tres de sus caras, formando combinaciones simétricas de cruces y motivos florales. En el centro, de la cara principal, se documenta un medallón con cuatro pétalos. La pieza nos remite a paralelos muy cercanos hallados en Mérida, y para los que Cruz Villalón supone un mismo taller (1985,243, láms:245, 246 y esp. 244). Esta autora indica el probable origen bizantino de tales paralelos que, por calidad y ejecución, son equiparables a nuestro cimacio (Schlunk,1947,257). Interesa observar que el esquema decorarivo, ya "degenerado", tuvo un éxito especial en la Lusitania y, especialmente, en el sur, donde logra una notable aceptación (Badajoz, Sines, Beja, Mértola) - (Cruz Villalón, 185,243).

La segunda pieza se define claramente como un tenante de altar, esta vez localizado como peldafio de una capilla de la iglesia de parroquial de $\mathrm{N}^{2}$. $\mathrm{Sr}^{2}$. de la Asunción de la localidad de Segura de León. Se trata de otro elemento marmóreo de buena calidad, aunque no asimilable al anterior.

De cuerpo ortoédrico, responde claramente al tipo I de la citada autora extremeña, conservando sólo las partes correspondiente a la basa y fuste con cruz. Sus paralelos se encuentran dispersos por todo el siglo VII peninsular pero es, de nuevo, el área meridional de la Lusitania (Badajoz, Mérida, Sines, Torrâo) y sus tierras betúricas (Puebla de Reina, Usagre) la que presenta la mayor concentración y los ejemplares más cercanos (Vilialón, 1985,221; Schlunk, 1947,256).

La tercera, y última, pieza corresponde a un capitel y parte del fuste de una columna, utilizada como pilastra de agua bendita en la iglesia se Santiago el Mayor de la localidad, hoy onubense, de Arroyomolinos de León. Tanto sus dimensiones, como el arte de fabricación, presentan una pieza de peor calidad que las anteriores, con un estado de conservación lamentable en el que sólo la corona inferior, de hojas de acanto, y un motivo de doble cruz en círculo (o, en términologfa céltica, "de rueda"), entre los restos de la superior, se conservan completos. La ejecución, con mínimo volúmen y máxima geometrización, permite considerarlo como una pieza de arte tardío o local, muy alejada de los capiteles de Mérida o Córdoba donde son excepción (Cruz Villalón,1985,252, tipo C1; Puertas Tricas, 1975, lám.8; Camps Cazorla,1963, fig:275). Tiene, también, una repartición meridional que se documenta en ejemplares cercanos de Sines y Beja (Almeida,1962,fig:128 y 1968/1970, fig:3).

\section{CONCLUSIONES Y CRONOLOGLA}

A la espera de poder realizar los necesarios sondeos y actuaciones preventivas, este trabajo pretende destacar la presencia de un conjunto de carácter supuestamente monástico, caracterizado por construcciones amuralladas entre las que destaca una iglesia o basilica. Según las técnicas y resultados edilicios, tales restos parecen adscribirse al perfodo visigodo, aunque bien pudieron perdurar durante un tiempo indefinido, encuadrándose en lo que se ha denominado Arquitectura Prerrománica o, como preferimos, Postvisigoda.

Situado en el Suroeste de Extremadura, tal conjunto tiene la importancia de enriquecer y ampliar notablemente una implantación comarcal con cierta intensidad durante la Alta Edad Media. A las piezas halladas en los entornos, han de sumarse los datos e inscripciones que informan sobre la 
presencia de basilicas en Jerez, Burguillos, Valverde de Burguillos y Brovales (Calero, 1987, 395396), directamente comunicadas por cordeles y cañadas con el paraje frexnense en estudio. Se incluyen en la misma comarca ardileña los importantes testos de La Mara de San Blas (Fig.:1).

En general, como demuestra el estudio de las piezas de este trabajo, se reafirman las conclusiones planteadas por Jose Angel Calero (Calero, 1987; Calero y Mesa, 1985,127-133) sobre la unidad de estilo y actuación entre las tierras betúricas y las sudlusitanas (del Oeste de la provincia pacense y el Alentejo). Parece confirmado el dominio de Emerita, sucedido por Pax Iulia, entre los siglos V y VIII (Calero,1987,397; Cruz Villalón, 1987 y 1983,11).

El monasterio de San Miguel se localiza, como otros similares, en un punto estratégio de cruce de caminos, que comunican la comarca con Mérida y Portugal. Las aguas curativas y la fertilidad del emplazamiento, excepcional en los entornos, presentan un panorama reconocido en conjuntos monásticos como El Trampal, Melque, Bande o Baños (Caballero, 1987,64; Cerrillo, 1983, $134 \mathrm{y} \mathrm{ss}$.).

De sus restos superficiales pueden extraerse conclusiones importantes: básicamente se trata de un conjunto amurallado, o al menos cercado, con construcciones de cierta entidad.

En general, es evidente que parte de làs estructuras más antiguas fueton edificadas con sillares y materiales procedentes de otras edificaciones, romanas o paleocristianas, del entorno nertobriguense (Berrocal, 1989-1990). Además, por el fuerte substrato céltico, pudiera documentarse un centro de culto prerromano a Ategina o Endovélico, como ocurre con dicha diosa en Santa Lucía del Trampal (Caballero et alii,1991). En este sentido no es vano mencionar la vecindad de la ateginense Turóbriga (en Bienvenida o Aroche, véase López Melero,1986), ni que el principal santuario a Endovélico, la ermita de San Miguel de Mota (Êvora), esté dedicada al mismo Arcángel y tenga, entre sus paredes, importantes restos visigodos (Villalón,1985). Su caracter ctónico y salutifero queda reforzado por el entorno hundido y las aguas medicinales, cuya confirmación estaria en el fondo de esta implantación.

Aparte de un gran edificio, cuya función no es posible concretar, destacan los restos de una iglesia altomedieval de posible planta cruciforme (quizá, libre) y ábside central de herradura, franqueado por otros dos. No podemos definir el tipo o las dimensiones de las naves, pero todos sus restos parecen presentar una construcción cultual equiparable a Santa Marfa de Melque, San Pedro de La Mata o Santa Comba de Bande (Caballero y Latorte, 1980,711 y ss.), aunque, en planta, ande muy proxima a la iglesia del Gatillo (Caballero et alii, 1991, 473 y ss.).

Desconocemos, también, si los ábsides laterales fueron construidos junto con el central o son resultado de posteriores reformas. Sobre sus funciones, pese al abovedamiento, nos inclinamos a considerarlos más sacristŕas que alares. Convienen muy bien a la propuesta de localización del preparatorium, al norte y del sacrarium, al sur del ábside, que planteb Caballero Zoreda. A ello contribuye el sistema y dimensiones de los accesos que los comunican con el altar central. Así a la estancia septentrional, que según las Reglas correspondería al preparatorium, se accede por una puerta mayor y más cercana al transepto y la nave.

Sus funciones exigian una vía de comunicación menos restringida, al contrario que el sacrarium, al que se accede por una puerta menor y emplazada al fondo del ábside (sobre tan confuso tema remitimos a Puertas Tricas, 1975,134-154 y Caballero Zoreda, 1987,90 y ss.).

Respecto a los atranques exteriores, dirigidos al Oriente, suponemos que podrían formar parte de otras construcciones relacionadas con el culto y, especialmente, con algunas de las citadas sacristías. Así pudieran ser los discutidos donarium, al norte con el preparatorium, y thesaurum, al sur y telacionado con el sacrarium (Caballero y Bueno, 1989,285). 
Cronológicamente no tenemos datos o indicios que nos permitan concretar más allá de la categoría visigoda del ábside central. Si la mayor frecuencia de este tipo de estructuras de planta en herradura (inscrita en rectángulo) puede datarse en pleno siglo VII, la fecha bien documentada de El Gatillo demuestra que tales construcciones pueden retrasarse, cuando menos, al siglo precedente (Caballero, Galera y Garralda, 1991,480 y 487), lo que vendría a coincidir con la tradición escrita sobre los Santos Abates.

La ocupación, sin embargo, pudo sufrir diversas incidencias que perpetuaran su uso hasta épocas post-visigodas y, por ello, algunas estructuras pudieran llevarse hasta finales del siglo IX d.C., como resultado de fuertes concentraciones de "poblacion hispanogoda residual" (Cerrillo, 1981, 242243 y 1986; Caballero, 1989, 113 y ss.) y de la ausencia generalizada de restos islámicos (entre medio centenar de yacimientos arqueológicos prospectados y una decena de excavaciones abiertas en el Ardila, sólo contamos con la localización, que realizamos en 1988, de la beréber Sigunsa, sobre el castro de Gigonza, Segura de Lénn).

El sistema amurallado aboga, aunque no necesariamente, por esta perduración tardía (como en Melque o Arcavica, Caballero,1989,123), justificada por el desarrollo de la presencia islámica en Extremadura, con continuados levantamientos muladies, cristianos y berberíscos hasta mediados del siglo X. En tal sentido, las actuaciones bélicas se acumulan, excepcionalmente, en los territorios del sur de Badajoz a finales del IX' (878, Alfonso III en el Oxiferium Montem; 885, Marwân 'el gallego' en Fuente de Cantos y Montemolin; 889, Marwân, en Fuente de Cantos) que culminan en el luvioso invierno del 898 , cuando un ejéxcito al mando del príncipe Abân bate a los descendientes de Marwân en las cercanías de Fuente de Cantos (Terrón, 1985,310 y ss, 343). 


\section{BIBLIOGRAFIA}

AlmeidA, F. Cunha da, 1962, "Arte visigotica em Portugal." OArgP, NV, Lisboa.

... 1968/1970, "Sines visigórica.", Arquive de Beja,XXV-XXVII, Beja.

ANDRES ORDAX, S., 1981, "La basílica hispanovisigoda de Alcuescar (Cáceres)." Norba, 2, Cáceres.

... 1983, Arte hispanovisigodo en Extremadura. I.C.El Brocense, Cáceres.

... 1986, "Huellas Visigodas en la Baja Extremadura." Historia de la Baja Extremadura (Terrón Albarrán, coord.), 193-227, Badajoz.

Barpientos Aifageme, G., 1990, Geografia de Extremadura. Biblioreca Popular Extremeña, Universitas Edit, Badajoz, 201 pp.

Berrocal RanGel, L., 1989/1990, "Cambio cultural y Romanización en el Suroeste peninsular." Anas, 23,103-122, Mérida.

.. 1992, Los Pueblos Célticos del Suroeste Peninsular. Tesis Doctoral inédita, Universidad Autónoma de Madrid, $2700 \mathrm{p}$.

CABALIERO ZOREDA, L., 1977/1978, "La forma en herradura hasta el siglo VIII." $A E_{s p} A, 50-51$, Madrid.

... 1987, "Hacia una propuesta tipológica de los elementos de arquitectura de culto cristiano de época visigoda. Nuevas iglesias de El Gatillo y El Trampal." II CAMEI, 61-98, Madrid.

... 1989, "Pervivencia de elementos visigodos en la transición al mundo medieval." III CAME, vol.I, 113134.

CABailero, L. y Bueno, J., 1989, "De nuevo a propósito de la basilica de Recópolis." AEspA,62, 283-291.

CABALIERO, L. y LATORRE MACARRON, J.I.,1980, La iglesia y el monasterio visigodo de Santa Marla de Melque (Toleda). Arqueologia y Arquitectura. San Pedro de la Mata (Toledo) y Santa Comba de Bande (Ourense), EAE, 109, 752 pp, Madrid.

Caballero Zoreda, L. y Mateos Cruz, P., 1991, "Excavaciones en Santa Eulalia de Mérida." Extremadura Arquealógica, II, 525-546, Cáceres-Mérida.

Caballero Zoreda, L. y Rosco Madruga, J., 1988-a, "Iglesia visigoda de Santa Lucla del Trampal, Alcuéscar (provincia de Cáceres). Primera campaña de rrabajos arqueológicos. 1983-1984." Extremadura Arqueolbgica, 1, 231-250, Salamanca.

... 1988-b, "Iglesia de El Gaxillo de Arriba, finca de la Matallana (Municipio y provincia de Cáceres). Informe preliminar de la primera campaña de excavaciones arqueológica. Octubre-Noviembre 1985." Extremadura Arqueologica, 1,251-261, Salamanca.

Cabailero, L; Almagro-Gorbea, A.; Madronero, A. y GrandA, A., 1991, "La iglesia de época visigoda de Santa Lucía del Trampal, Alcuescar (Cáceres)." Extremadura Arqueológica, II,497-524

CABallero, L; Galers, V. y Garralda, M" Dolores, 1991, "La iglesia de época paleocristiana y visigoda

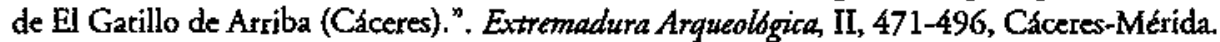

Calero Carretero, J. A., 1987, "El Plan del Sudoeste: relaciones hispano-portuguesa en época visigoda a la luz de los materiales arqueológicos de <<La Mata de San Blas >." I Jornadas Ibéricas de investigadores en Ciencias Humanas y Sociales (Olivenza, 1985), 387-397, Salamanca.

Calero Carretero, J. A y Mesa Garcia, J A, 1985, "El Plan del Sudoeste: Cuatro nuevas piezas de arquitectura decorativa visigoda procedentes de <<La Mata de San Blass>. Estzudios de Arqueologta Extremeña (Homenaje a Cánovas Pesini), 127-133, Badajoz.

CAMPS CAZORLA, E.,1953, M6dulos, proporiones y composición de la arquitectura califal cordobesa. Madrid. ... 1963, "El arte hispanovisigodo." Historia de España, III. (Menéndez Pidal, dtor,), Espasa Calpe, Madrid. Cerrilio y MarTin de CACERes, E., 1981, "Aproximación al estudio de las cabeceras rectangulares del siglo VII*." Zephyrus, XXXII-XXXIII, 233-243, Salamanca. 
... 1983, La bastica visigoda de Ibahemando. Cáceres.

... 1986, "Arqueología de la Religión. reflexiones sobre el caso hispạ́nico (siglos IV-VIII)." Los Visigodos. Historia y civilización. Antigüedad y Cristianismo, 3, 491 y ss.

CORzo SANCHEZ, R, 1978, "Génesis y función del arco de herradura." Al-Andalus, LXIII.

... 1989, Visigotico y Prerrománico. Serie Historia del Arte. Historia 16, Madrid.

Cruz Villalon, M., 1977, "Las piezas visigodas del museo de Badajoz. I Congreso Nacional de Historia del Arte, Trujillo.

.. 1983, "Los materiales de la escultura visigoda de Mérida." Norba, III, Cáceres.

... 1985, Mérida Visigoda. La escultura arquitectónica y litúrgica. Colección Roso de Luna, Badajoz, 456 pp.

DOMERGue, C., 1987, Catalogue des mines et des fonderies antiques de la Peninsule Iberique. 2 vols., Serie Archeologie, VIII, Casa de Velázquez, Madrid, 585 pp.

... 1990, Les mines de la Peninsule Ibérique dans l'Antiquité romaine. Collect. de l'Ecole Française de Rome, 127,625 pp.

Garcia Martin, P., 1988, La Ganaderia Mesteña en la España Borbónica (1700-1836). Serie Estudios. Ministerio Agricultura, Pesca y Alimentación.

Gonzalez Ceballos, S., 1988, La luvia en Extremaduta, Cuadernos Populares, 24, Salamanca, 36 pp.

MAPA De Cultivos, 1988, Mapa de cultivos y aprovechamientos de la provincial de Badajoz. Memoria, E. 1:200.000, Ministerio de Agricultura, Pesca y Alimentación, Madrid, 192 pp.

OYOLA FABIAN, A., 1990, "De Re Acheologica, o los trabajos y los dias de un equipo." Frontera Abierta, 1, 20-24, Fregenal.

Palol, P. de, 1954, "Arqueología paleocristiana y visigoda" IV Congr. Internacional Ciencias Prehistóricas y Protohistoricas, Zaragoza.

... 1967, Arqueologia cristiana de la España romana, siglos IV-VI. CSIC, Madrid-Valladolid.

Perez Diaz, A., 1988, Cambios y problemática de la dehesa (El Suroeste de Badajoz). Publ. Universidad Extremadura, Cáceres, 183 pp.

PUERTAS TRICAS, R., 1975, Iglesias hispánicas (siglos IV-VIII). Testimonios literarios. Temas de Arte, 4 , MEyC, Madrid, 314pp.

Quntero Carrasco, J., 1981, Historia de Fregenal de la Siena. Don Benito.

SANCHEZ CID, A. M., 1843, Epitome histórico de la Gran Villa de Fregenal, cuyas interesantes noticias han sido tomadas de antiguos y modernos autores. Sevilla.

SOLANO DE FIGUEROA Y ALTAMIRANO, J., 1930 (edicc manuscrito del siglo XVII), Historia eclesiastica de la ciudad y obispado de Badajoz Badajoz.

SCHLUNK, H, 1947, Arte visigodo. «<Ass Hispaniae»>,II, Plus-Ultra, Madrid

Terron AlbarRan, M., 1986, "Historia política de la Baja Extremadura en el Petiodo Islámico." , Histaria de la Baja Extremadura (Terrón Albarrán, drtor.), I, Badajoz, $285-557$. 